Article

\title{
Corrosion Inhibition of High Speed Steel by Biopolymer HPMC Derivatives
}

\author{
Shih-Chen Shi * and Chieh-Chang Su \\ Department of Mechanical Engineering, National Cheng Kung University (NCKU), No. 1 University Road, \\ Tainan 70101, Taiwan \\ * Correspondence: scshi@mail.ncku.edu.tw; Tel.: +886-6-275-7575 (ext. 62176); Fax: +886-6-2352-973
}

Academic Editor: Wen-Hsiang Hsieh and Peter J. Uggowitzer

Received: 28 June 2016; Accepted: 20 July 2016; Published: 23 July 2016

\begin{abstract}
The corrosion inhibition characteristics of the derivatives of biopolymer hydroxypropyl methylcellulose (HPMC), hydroxypropyl methylcellulose phthalate (HPMCP), and hydroxypropyl methylcellulose acetate succinate (HPMCAS) film are investigated. Based on electrochemical impedance spectroscopic measurements and potentiodynamic polarization, the corrosion inhibition performance of high speed steel coated with HPMC derivatives is evaluated. The Nyquist plot and Tafel polarization demonstrate promising anti-corrosion performance of HPMC and HPMCP. With increasing film thickness, both materials reveal improvement in corrosion inhibition. Moreover, because of a hydrophobic surface and lower moisture content, HPMCP shows better anti-corrosion performance than HPMCAS. The study is of certain importance for designing green corrosion inhibitors of high speed steel surfaces by the use of biopolymer derivatives.
\end{abstract}

Keywords: corrosion; HSS; biopolymer; HPMC; green inhibitor

\section{Introduction}

Currently, there are three primary methods of corrosion control: reducing metal oxidation [1], decreasing corrosion of corrosive liquids [2], and isolating metal from the corrosive environment via dry films [3-5]. In a liquid environment, the common approach is to add corrosion inhibitors to form a physical adsorption layer on the surface, thereby blocking the penetration of active substances and reducing corrosion [6-8]. However, most inhibitors are harmful and can contaminate the global environment. Thus, several researchers have investigated the effects of polymeric corrosion inhibitors, such as polyamide compounds [9], polyacrylic acid [10], polymeric materials [11], and cellulosic polymers [12], which show considerable promised anticorrosion behavior.

According to the requirements of the Paris climate agreements and sustainable development, extensive studies on green materials for anti-corrosive films have recently been conducted [13-16]. The objective of the present study is to evaluate the anti-corrosion performance of biopolymer hydroxypropyl methylcellulose (HPMC) derivatives in a saline solution. HPMC was extracted from high purity wood pulp from natural forests. Owing to its high film forming ability [17] and flexibility [18], it has been widely employed in the medical field [19-21] and the food industry [22]. Meanwhile, HPMC has a good capability for distributing and preventing grease and gas penetration [23], and is therefore used in sustainable manufacturing [24]. Moreover, owing to its biocompatibility [25] and decomposability [26,27], it is also used as a corrosion inhibitor [28-31]. Traditional HPMC is soluble in water; thus, it is not suitable for a water and high humidity environment. It is usually added to liquid as a corrosion inhibitor. In the sustainable manufacturing applications, solid films were used to replace the solution-type inhibitor for the environmental-friendly considerations. Therefore, acetate, succinate, and phthalates were added to HPMC to obtain hydroxypropyl methylcellulose phthalate (HPMCP) and hydroxypropyl methylcellulose acetate 
succinate (HPMCAS). They not only preserve the characteristics of HPMC, but are also insoluble in water, and function well in strong acid environments. The material details of HPMCP and HPMCAS are listed in Table 1. The composition of high speed steel is listed in Table 2.

Table 1. The compositions list of hydroxypropyl methylcellulose phthalate (HPMCP) and hydroxypropyl methylcellulose acetate succinate (HPMCAS).

\begin{tabular}{ccccccc}
\hline Materials & $\begin{array}{c}\text { Molecular } \\
\text { Weight }\end{array}$ & $\begin{array}{c}\text { Methoxy } \\
\text { Content (\%) }\end{array}$ & $\begin{array}{c}\text { Hydroxypropoxy } \\
\text { Content (\%) }\end{array}$ & $\begin{array}{c}\text { Phthalyl } \\
\text { Content (\%) }\end{array}$ & $\begin{array}{c}\text { Acetyl } \\
\text { Content (\%) }\end{array}$ & $\begin{array}{c}\text { Succinoyl } \\
\text { Content (\%) }\end{array}$ \\
\hline HPMCP & 37,900 & $20.0 \% \sim 24.0 \%$ & $6.0 \% \sim 10.0 \%$ & $21.0 \% \sim 27.0 \%$ & & \\
HPMCAS & 18,000 & $20.0 \% \sim 24.0 \%$ & $5.0 \% \sim 9.0 \%$ & & $5.0 \% \sim 9.0 \%$ & $14.0 \% \sim 18.0 \%$ \\
\hline
\end{tabular}

Table 2. Composition of high speed steel.

\begin{tabular}{ccccccccccccc}
\hline Composition & $\mathbf{C}$ & $\mathbf{M n}$ & $\mathbf{C r}$ & $\mathbf{W}$ & $\mathbf{V}$ & $\mathbf{M o}$ & $\mathbf{S i}$ & $\mathbf{P}$ & $\mathbf{S}$ & $\mathbf{N i}$ & $\mathbf{C u}$ & $\mathbf{F e}$ \\
\hline SKH51 & 0.82 & 0.24 & 4.20 & 6.50 & 2.05 & 5.78 & 0.23 & 0.02 & 0.01 & 0.08 & 0.12 & 79.95 \\
\hline
\end{tabular}

\section{Results and Discussion}

\subsection{Film preparation and Characteristics Measurement}

The film thickness can be controlled by precisely adjusting the drop amount, as shown in Figure 1. HPMCP-1, HPMCP-2 and HPMCP-3 correspond to 600, 1200 and $1800 \mu \mathrm{L}$, respectively. The corresponding thicknesses are 200, 360, and $580 \mu \mathrm{m}$, respectively. HPMCAS-1, HPMCAS-2 and HPMCAS-3 correspond to 600, 1200 and $1800 \mu \mathrm{L}$, respectively. The corresponding thicknesses are 180, 360 , and $560 \mu \mathrm{m}$, respectively. The results show that the thickness of the HPMCP and HPMCAS films could be accurately adjusted and controlled.

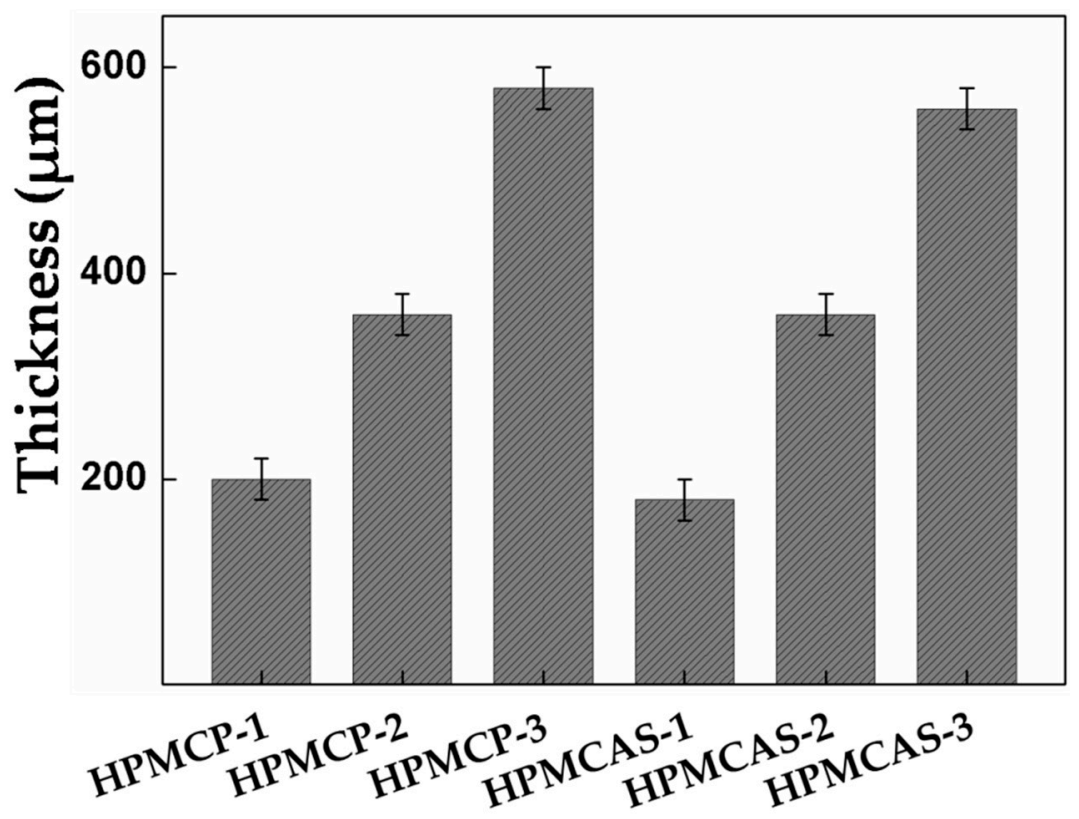

Figure 1. Thickness distributions of HPMCP and HPMCAS.

Raman spectroscopy was utilized to investigate the material characteristics of HPMC derivatives. The Raman spectra of HPMCP and HPMCAS are presented in Figure 2. The characteristic peaks of HPMC are depicted, including those at $1360 \mathrm{~cm}^{-1}$ (COH bending) and $1450 \mathrm{~cm}^{-1}\left(\mathrm{CH}_{2}\right.$ twist) [32]. Moreover, a comparison of the two curves of HPMCP and HPMCAS shows that there is no obvious 
different absorption peak. It reflects that although phthalate, acetate, and succinate were added to HPMC to meet the requirements of acid and moisture resistance, HPMCP and HPMCAS preserved the structural properties of HPMC. Therefore, Raman spectroscopy could be used to assess the material, decomposability, and uniformity properties of HPMCP and HPMCAS [32,33].

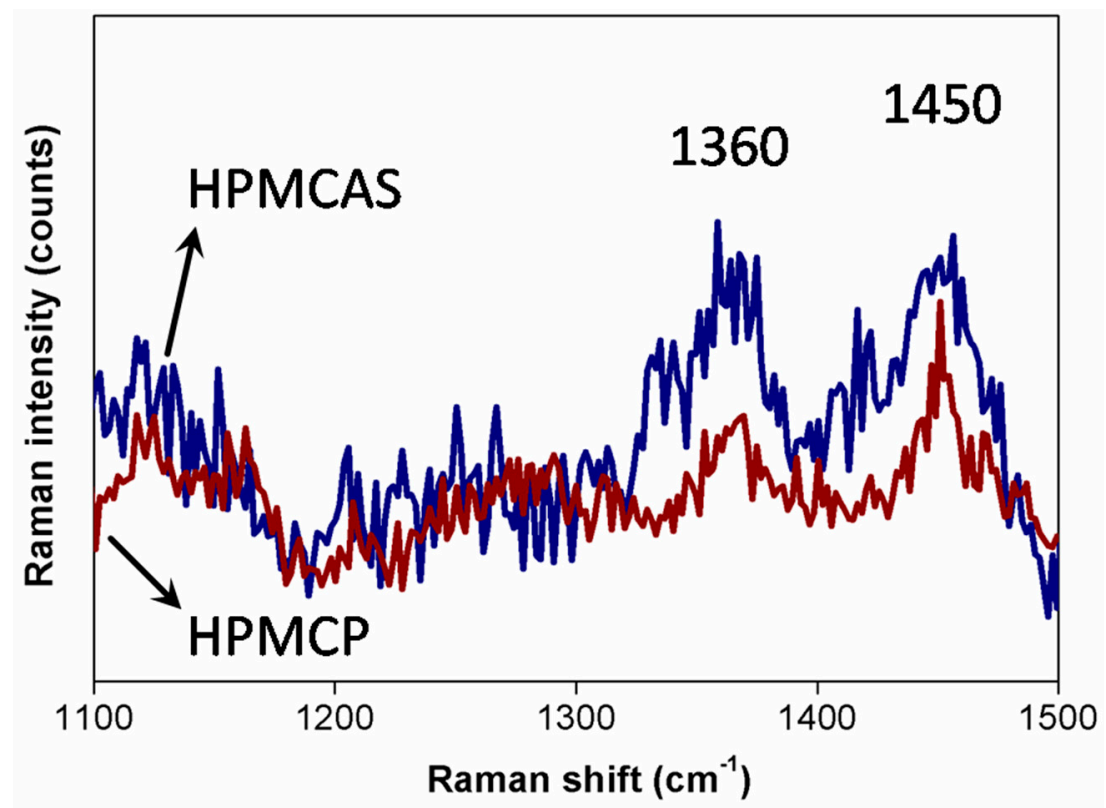

Figure 2. Raman spectroscopy graphs of HPMCP and HPMCAS.

\subsection{Anti-Corrosion Behavior}

Figure 3a shows the Nyquist plots of the four measured samples. The first sample is uncoated high speed steel (HSS). A series of samples are denoted HPMCP-1, HPMCP-2 and HPMCP-3, respectively. Figure $3 \mathrm{~b}$ shows the Nyquist plots of HPMCAS with varying thickness. It can be seen that the left part was a semi-circle, and the right part was an incomplete semi-circle. Hence, it can be determined that the plot is comprised of two time constants. The equivalent circuit diagram shown in Figure 4 was used to simulate the actual conditions [34].
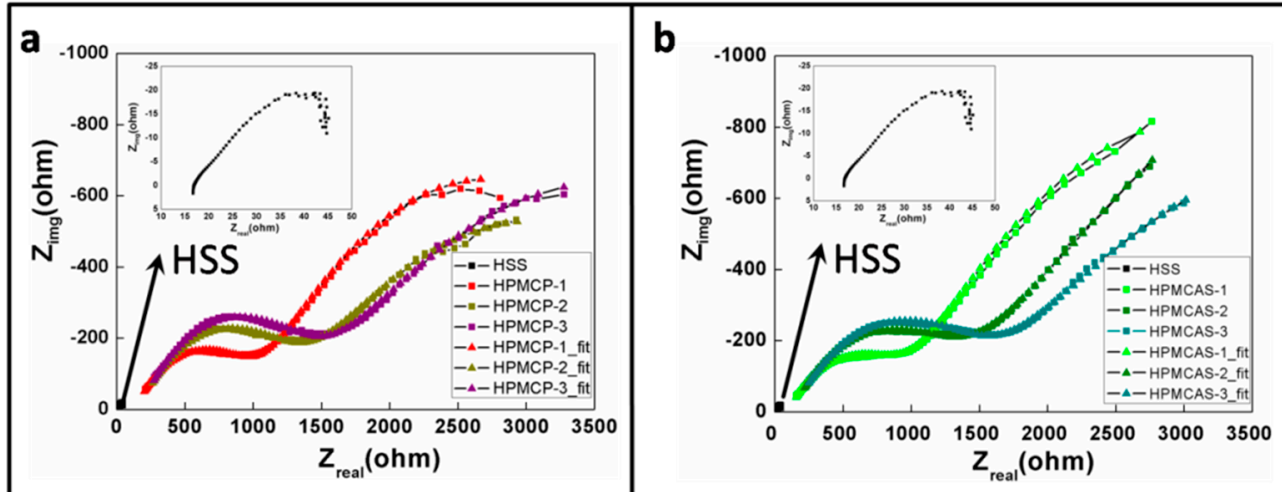

Figure 3. Nyquist plot of (a) HPMCP with varying thickness, where the inset is the Nyquist plot of uncoated high speed steel (HSS); (b) HPMCAS with varying thickness.

As shown in Figure 4, Rs represents the resistance of saline solution; Rf represents the resistance of the HPMC derivatives film; CPE_film is the capacitance of the HPMC film; Rct is the resistance between the steel and solution, also called the charge-transfer resistance; CPE_dl is the capacitance of the double electrode layer. CPE was used in this study as opposed to the capacitance in the traditional 
equivalent circuit model as there was an uneven current potential distribution; CPE would be more accurate according to previous studies [35-37].

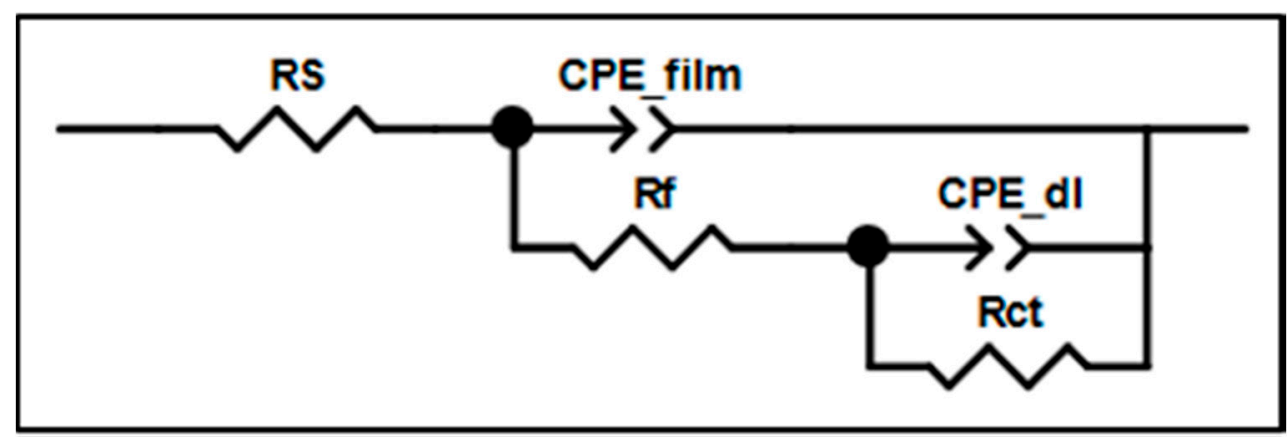

Figure 4. EIS equivalent circuit diagram.

In the equivalent circuit diagram, Rf corresponds to the left semi-circle in Figure 3; the larger the $\mathrm{Rf}$, the larger the radius in the Nyquist plot, and the better the anti-corrosion ability. Rct corresponds to the right semi-circle. As the aim of the current study is to investigate the anti-corrosion ability of the film, we focus on Rf.

The original data was fitted with an equivalent circuit diagram, and the fitting data is shown in Table 2. The film resistance (Rf) of HPMCP-1, HPMCP-2, and HPMCP-3 are 989, 1260, and $1368 \Omega$, respectively. The film resistance of HPMCAS-1, HPMCAS-2, and HPMCAS-3 are 987, 1339 and $1535 \Omega$, respectively. For both materials, the film resistance increased with increasing film thickness, as did the penetration depth [38], indicating enhanced resistance ability with increasing film thickness.

By comparing the Rf for HPMCP and HPMCPAs, the results clearly demonstrate that HPMCP and HPMCAS were at the same scale. However, the increase in impedance for the HPMCAS can be attributed to it having a better hydrophilicity than HPMCP. The high capacitance, CPE_film, is related to the high extent at which water has penetrated the film [39]. Comparison of CPE_film-T for HPMCAS and HPMCP shows that the former had a larger CPE_film-T, i.e., greater moisture content. This is consistent with the experiment on contact angles. Compared to HPMCP, HPMCAS showed a smaller contact angle, namely, a better hydrophilic property. Higher hydrophilicity of HPMCAS compared to HPMCP and bare HSS may result from high-wettability. This leads to an increased concentration of corrosive substance on the HSS surface.

Previous results show that HPMCP and HPMCAS films had demonstrated promising anti-corrosion behavior. The potentiodynamic polarization (PP) method was further used to record the variation in current and potential during the experiment. The polarization curves for HPMCP and HPMCAS with different thicknesses are shown in Figure 5. The curves are divided into cathodic and anodic polarization. Cathodicpolarization is the section before the lowest point, representing hydrogen reduction in the experiment: $2 \mathrm{H}^{+}+2 \mathrm{e}^{-} \rightarrow \mathrm{H}_{2}$. Anodic polarization is the right section after the lowest point, representing metal oxidation in the experiment: $\mathrm{M} \rightarrow \mathrm{M}^{\mathrm{n}+}+\mathrm{ne}^{-}$.

The bottom point of the curve represents the corrosion potential. The corrosion current (Icorr) was measured using Tafel extrapolation. Within $50 \mathrm{mV}$ of the corrosion potential, a linear region, called the Tafel region, was obtained. The tangent lines of cathodic polarization (slope $\beta a$ ) and anodic polarization (slope $\beta c$ ) intersect in the horizontal axis at the point of corrosion current (Icorr), which represents the corrosion rate. In the present study, Icorr was used to evaluate the anti-corrosion ability of the film $[40,41]$, the data of which are shown in Table 3.

The electrochemical corrosion measurements of HSS, HPMCP and HPMCAS are shown in Table 4. The Tafel plots for the HPMCP yield corrosion potentials of Ecorr $=-388.1,-294.9$, and $-230.5 \mathrm{mV}$ for HPMCP-1, HPMCP-2, and HPMCP-3, respectively, which are more positive than that of the bare HSS, where Ecorr $=-547.5 \mathrm{mV}$. Moreover, the corrosion current (Icorr) of HPMCP-1, HPMCP-2, 
and HPMCP-3 were $6.8,5.2$, and $0.8 \mu \mathrm{A} / \mathrm{cm}^{2}$, respectively, which are significantly lower than that of the HSS sample $\left(26.3 \mu \mathrm{A} / \mathrm{cm}^{2}\right)$.
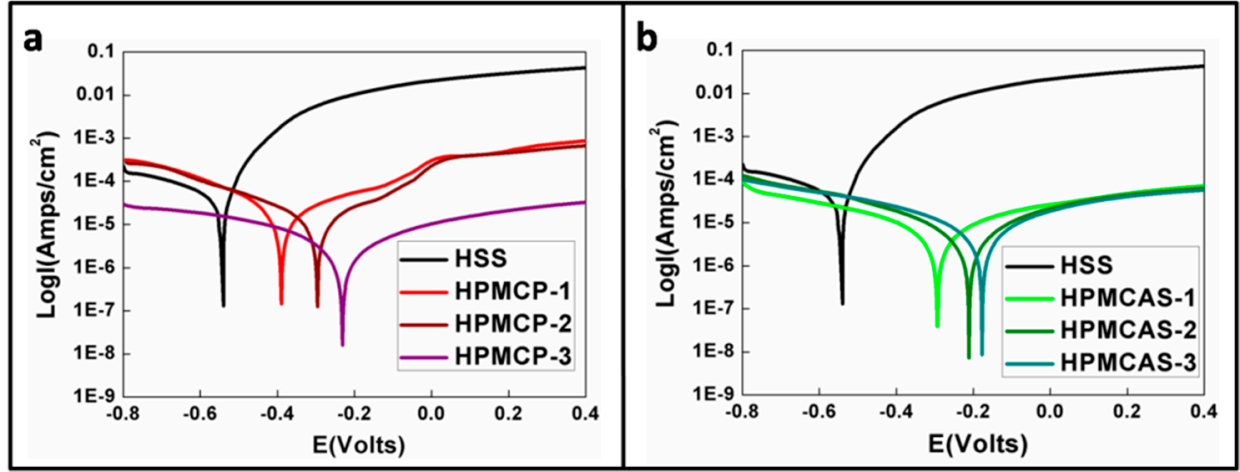

Figure 5. Polarization curve of (a) HPMCP with varying thickness; (b) HPMCAS with varying thickness.

Table 3. EIS fitting results and contact angles of HPMCP and HPMCAS coated electrodes.

\begin{tabular}{cccccc}
\hline Item/Index & Rs $(\boldsymbol{\Omega})$ & $\mathbf{R f}(\boldsymbol{\Omega})$ & $\mathbf{C P E} \_$film-T(F) & $\mathbf{C P E}$ fim-P & Contact Angle $\left({ }^{\circ} / \mathbf{H}_{\mathbf{2}} \mathbf{O}\right)$ \\
\hline HPMCP-1 & 128 & 989 & $3.49 \times 10^{-5}$ & 0.40342 & 68.8 \\
HPMCP-2 & 157 & 1260 & $1.85 \times 10^{-5}$ & 0.42213 & 68.6 \\
HPMCP-3 & 160 & 1368 & $1.34 \times 10^{-5}$ & 0.44124 & 69.4 \\
HPMCAS-1 & 90 & 987 & $5.49 \times 10^{-5}$ & 0.38172 & 63.3 \\
HPMCAS-2 & 115 & 1339 & $2.76 \times 10^{-5}$ & 0.39806 & 65.0 \\
HPMCAS-3 & 120 & 1535 & $2.42 \times 10^{-5}$ & 0.39101 & 63.0 \\
\hline
\end{tabular}

Table 4. Electrochemical corrosion measurement of HSS, HPMCP and HPMCAS coated electrodes.

\begin{tabular}{ccccc}
\hline Item/Index & $-\mathbf{E}_{\text {corr }}(\mathbf{m V})$ & $\mathbf{I}_{\text {corr }}\left(\boldsymbol{\mu} \mathbf{A} / \mathbf{c m}^{\mathbf{2}}\right)$ & $\beta \mathbf{a}(\mathbf{m V} / \mathbf{d e c})$ & $\beta \mathbf{c}(\mathbf{m V} / \mathbf{d e c})$ \\
\hline bare HSS & 547.5 & 26.3 & 65.4 & -159.9 \\
HPMCP-1 & 388.1 & 6.8 & 124.9 & -99.3 \\
HPMCP-2 & 294.9 & 5.2 & 112.2 & -119.9 \\
HPMCP-3 & 230.5 & 0.8 & 117.5 & -108.0 \\
HPMCAS-1 & 294.4 & 1.8 & 119.5 & -114.5 \\
HPMCAS-2 & 211.1 & 1.4 & 105.5 & -108.4 \\
HPMCAS-3 & 176.7 & 1.7 & 102.6 & -105.2 \\
\hline
\end{tabular}

The Tafel plots for the HPMCAS yield a corrosion potential of Ecorr $=-294.4,-211.1$, and -176.7 mV for HPMCAS-1, HPMCAS-2, and HPMCAS-3, respectively, which are more positive than that of the bare HSS. Moreover, the corrosion current (Icorr) for HPMCAS-1, HPMCAS-2, and HPMCAS-3 was $1.8,1.4$, and $1.7 \mu \mathrm{A} / \mathrm{cm}^{2}$, respectively, which are significantly lower than that of the HSS. From Table 3, it can be seen that for HPMCP and HPMCAS, the corrosion current decreased with increasing film thickness, indicating a reduced corrosion rate. Thus, there is a positive correlation between film thickness and the corrosion resistance performance.

Comparison of HPMCP-3 and HPMCAS-3 shows that the corresponding Icorr decreased considerably when we used the phthalate function group, suggesting the formation of hydrophobic properties. The electrochemical measurement results show that the HPMCP film provided better protection against corrosion of the HSS than the HPMCAS.

In terms of viscosity, the values for HPMCP and HPMCAS were 100 and $200 \mathrm{mPa} \cdot \mathrm{s}$, respectively. The high viscosity of HPMCAS resulted in poor film formation, causing defects and inferior smoothness of the film [42], and, therefore, poor corrosion resistance. HPMCP had low material viscosity, hydrophobic surface and low moisture content resulted in promising corrosion resistance performance. 


\section{Materials and Methods}

\subsection{Film Preparation and Characteristics Measurement}

First, $10 \mathrm{~g}$ of HPMCP and HPMCAS powders (Shin-Etsu Chemical Co., Ltd., Tokyo, Japan) were mixed with $18 \mathrm{~mL}$ water and $72 \mathrm{~mL}$ alcohol. The solution was stirred at room temperature until all particles were dissolved. A micropipette was used to draw up 600-1800 $\mu \mathrm{L}$ of the mixed solution and to deposit it on polished high-speed steel. A film was then formed after 1-day rest under normal temperature and pressure conditions. A 3D scanner (Keyence, VK9710, Osaka, Japan) was used for the thickness measurement.

The Raman spectra were recorded using a micro-Raman spectrometer (Renishaw, New Mills, UK). The contact angles were measured using a First Ten Angstroms FTA-1000B (Portsmouth, VA, USA) at ambient temperature. Water droplets were carefully dropped onto the surface of the samples, and the contact angle was determined from the average of three measurements at various positions on the sample.

\subsection{Anti-Corrosion Behavior}

The corrosion potential and corrosion current of samples were electrochemically measured by the PP method. The working electrode was made of Teflon to grip the high speed steel test piece. A saturated calomel electrode was used as the reference electrode to measure the potential. The auxiliary electrode was a platinum electrode to conduct current. The output potential current was controlled and measured by a potentiostat. The electrolyte was a $0.5 \mathrm{M}$ saline solution.

EIS were recorded on an AC Impedance Analyzer (HIOKI 3533-05, Nagano, Japan). The frequency range was $200,000-0.01 \mathrm{~Hz}$, and the amplitude was $0.01 \mathrm{~V}, 10$ points/decade.

\section{Conclusions}

(1) The corrosion resistance performance of green polymer material HPMC derivatives was demonstrated.

(2) Both EIS and PP suggested promising corrosion resistance performance of HPMCP and HPMCAS.

(3) The film thickness of HPMC derivatives was positively correlated the corrosion resistance ability.

(4) HPMCP has hydrophobic surface and low moisture content; thus, it provided better anti-corrosion protection than HPMCAS.

Acknowledgments: The authors gratefully acknowledge the financial support for this project from the Ministry of Science and Technology in Taiwan (MOST 104-2221-E-006-057 and MOST 105-2221-E-006-069) and support in part from the Headquarters of University Advancement at the National Cheng Kung University, which is sponsored by the Ministry of Education, Taiwan. The authors also thank the Center for Micro/Nano Science and Technology, National Cheng Kung University (NCKU).

Author Contributions: S.C.S. conceived and designed the experiments; C.C.S. performed the experiments; S.C.S. and C.C.S. analyzed the data; S.C.S. and C.C.S. contributed reagents/materials/analysis tools; S.C.S. and C.C.S. wrote the paper.

Conflicts of Interest: The authors declare no conflict of interest.

\section{Abbreviations}

The following abbreviations are used in this manuscript:

$\begin{array}{ll}\text { NCKU } & \text { National Cheng Kung University } \\ \text { HPMC } & \text { hydroxypropyl methylcellulose } \\ \text { HPMCP } & \text { hydroxypropyl methylcellulose phthalate } \\ \text { HPMCAS } & \text { hydroxypropyl methylcellulose acetate succinate } \\ \text { HSS } & \text { high speed steel } \\ \text { PP } & \text { potentiodynamic polarization }\end{array}$




\section{References}

1. Kawahara, Y. High temperature corrosion mechanisms and effect of alloying elements for materials used in waste incineration environment. Corros. Sci. 2002, 44, 223-245. [CrossRef]

2. Bentiss, F.; Jama, C.; Mernari, B.; El Attari, H.; El Kadi, L.; Lebrini, M.; Traisnel, M.; Lagrenée, M. Corrosion control of mild steel using 3,5-bis(4-methoxyphenyl)-4-amino-1,2,4-triazole in normal hydrochloric acid medium. Corros. Sci. 2009, 51, 1628-1635. [CrossRef]

3. Hare, C. Corrosion control of steel by organic coatings. In Uhlig's Corrosion Handbook, 3rd ed.; John Wiley \& Sons: Hoboken, NJ, USA, 2000; pp. 971-983.

4. Kilmartin, P.A.; Trier, L.; Wright, G.A. Corrosion inhibition of polyaniline and poly (O-methoxyaniline) on stainless steels. Synth. Met. 2002, 131, 99-109. [CrossRef]

5. Chang, K.-C.; Hsu, M.-H.; Lu, H.-I.; Lai, M.-C.; Liu, P.-J.; Hsu, C.-H.; Ji, W.-F.; Chuang, T.-L.; Wei, Y.; Yeh, J.-M. Room-temperature cured hydrophobic epoxy/graphene composites as corrosion inhibitor for cold-rolled steel. Carbon 2014, 66, 144-153. [CrossRef]

6. Nordsveen, M.; Nešic, S.; Nyborg, R.; Stangeland, A. A mechanistic model for carbon dioxide corrosion of mild steel in the presence of protective iron carbonate films-part 1: Theory and verification. Corrosion 2003, 59, 443-456. [CrossRef]

7. Okafor, P.; Liu, X.; Zheng, Y. Corrosion inhibition of mild steel by ethylaminoimidazoline derivative in $\mathrm{CO}_{2}$-saturated solution. Corros. Sci. 2009, 51, 761-768. [CrossRef]

8. Liu, H.; Gu, T.; Zhang, G.; Wang, W.; Shuang, D.; Cheng, Y.; Liu, H. Corrosion inhibition of carbon steel in $\mathrm{CO}_{2}$-containing oilfield produced water in the presence of iron-oxidizing bacteria and inhibitors. Corros. Sci. 2016, 105, 149-160. [CrossRef]

9. Badr, S.; Abdallah, M. Preparation of new saturated polyamide compounds and its application as corrosion inhibitors for corrosion of carbon steel in hydrochloric acid solution. Zaštitamaterijala 2009, 50, $213-221$.

10. Umoren, S.A.; Li, Y.; Wang, F.H. Effect of polyacrylic acid on the corrosion behaviour of aluminium in sulphuric acid solution. J. Solid State Electrochem. 2010, 14, 2293-2305. [CrossRef]

11. Arthur, D.E.; Jonathan, A.; Ameh, P.O.; Anya, C. A review on the assessment of polymeric materials used as corrosion inhibitor of metals and alloys. Int. J. Ind. Chem. 2013, 4, 1-9. [CrossRef]

12. Arukalam, I.; Madufor, I.; Ogbobe, O.; Oguzie, E. Cellulosic polymers for corrosion protection of aluminium. Int. J. Eng. Tech. Res. 2015, 3, 2321-0869.

13. Abiola, O.K.; James, A. The effects of aloe vera extract on corrosion and kinetics of corrosion process of zinc in hcl solution. Corros. Sci. 2010, 52, 661-664. [CrossRef]

14. Eddy, N.O. Inhibitive and adsorption properties of ethanol extract of colocasiaesculenta leaves for the corrosion of mild steel in $\mathrm{H}_{2} \mathrm{SO}_{4}$. Int. J. Phys. Sci. 2009, 4, 165-171.

15. Kumpawat, V.; Garg, U.; Tak, R. Corrosion inhibition of aluminium in acid media by naturally occurring plant Artocarpus heterophyllus and Acacia senegal. J. Indian Counc. Chem. 2009, 26, 82-84.

16. Lebrini, M.; Robert, F.; Lecante, A.; Roos, C. Corrosion inhibition of C38 steel in 1Mhydrochloric acid medium by alkaloids extract from Oxandra asbeckii plant. Corros. Sci. 2011, 53, 687-695. [CrossRef]

17. Byun, Y.; Ward, A.; Whiteside, S. Formation and characterization of shellac-hydroxypropyl methylcellulose composite films. Food Hydrocoll. 2012, 27, 364-370. [CrossRef]

18. Al-Tabakha, M.M. HPMC capsules: Current status and future prospects. J. Pharm. Pharm. Sci. 2010, 13, 428-442. [CrossRef] [PubMed]

19. Brogly, M.; Fahs, A.; Bistac, S. Surface properties of new-cellulose based polymer coatings for oral drug delivery systems. Polym. Prepr. 2011, 52, 1054-1055.

20. Joshi, S.C. Sol-gel behavior of hydroxypropylmethylcellulose (HPMC) in ionic media including drug release. Materials 2011, 4, 1861-1905. [CrossRef]

21. Zhou, D.; Law, D.; Reynolds, J.; Davis, L.; Smith, C.; Torres, J.L.; Dave, V.; Gopinathan, N.; Hernandez, D.T.; Springman, M.K. Understanding and managing the impact of HPMC variability on drug release from controlled release formulations. J. Pharm. Sci. 2014, 103, 1664-1672. [CrossRef] [PubMed]

22. Bárcenas, M.E.; Rosell, C.M. Effect of HPMC addition on the microstructure, quality and aging of wheat bread. Food Hydrocoll. 2005, 19, 1037-1043. [CrossRef]

23. Villalobos, R.; Hernández-Muñoz, P.; Chiralt, A. Effect of surfactants on water sorption and barrier properties of hydroxypropyl methylcellulose films. Food Hydrocoll. 2006, 20, 502-509. [CrossRef] 
24. Shi, S.-C.; Huang, T.-F.; Wu, J.-Y. Preparation and tribological study of biodegradable lubrication films on Si substrate. Materials 2015, 8, 1738-1751. [CrossRef]

25. Ehrich, W.; Höh, H.; Kreiner, C. Biocompatibility and pharmacokinetics of hydroxypropyl methylcellulose (HPMC) in the anterior chamber of the rabbit eye. Klin. Monatsblatter Augenheilkd. 1990, 196, 470-474. [CrossRef] [PubMed]

26. Falguera, V.; Quintero, J.P.; Jiménez, A.; Muñoz, J.A.; Ibarz, A. Edible films and coatings: Structures, active functions and trends in their use. Trends Food Sci. Technol. 2011, 22, 292-303. [CrossRef]

27. Jiménez, A.; Fabra, M.; Talens, P.; Chiralt, A. Effect of lipid self-association on the microstructure and physical properties of hydroxypropyl-methylcellulose edible films containing fatty acids. Carbohydr. Polym. 2010, 82, 585-593. [CrossRef]

28. Arukalam, I.O.; Madufor, I.C.; Ogbobe, O.; Oguzie, E.E. Inhibition of mild steel corrosion in sulfuric acid medium by hydroxyethyl cellulose. Chem. Eng. Commun. 2014, 202, 112-122. [CrossRef]

29. Arukalam, I.; Madufor, I.; Ogbobe, O.; Oguzie, E. Experimental and theoretical studies of hydroxyethyl cellulose as inhibitor for acid corrosion inhibition of mild steel and aluminium. Quantum 2014, 1005, 1. [CrossRef]

30. Okechi Arukalam, I.; Chimezie Madufor, I.; Ogbobe, O.; Oguzie, E. Hydroxypropyl methylcellulose as a polymeric corrosion inhibitor for aluminium. Pigment Resin Technol. 2014, 43, 151-158. [CrossRef]

31. Arukalam, I.O. Durability and synergistic effects of ki on the acid corrosion inhibition of mild steel by hydroxypropyl methylcellulose. Carbohydr. Polym. 2014, 112, 291-299. [CrossRef] [PubMed]

32. De Veij, M.; Vandenabeele, P.; De Beer, T.; Remon, J.P.; Moens, L. Reference database of Raman spectra of pharmaceutical excipients. J. Raman Spectrosc. 2009, 40, 297-307. [CrossRef]

33. Shi, S.-C.; Wu, J.-Y.; Huang, T.-F.; Peng, Y.-Q. Improving the tribological performance of biopolymer coating with $\mathrm{MoS}_{2}$ additive. Surf. Coat. Technol. 2016. [CrossRef]

34. Freire, L.; Carmezim, M.; Ferreira, M.; Montemor, M. The electrochemical behaviour of stainless steel AISI 304 in alkaline solutions with different $\mathrm{pH}$ in the presence of chlorides. Electrochim. Acta 2011, 56, 5280-5289. [CrossRef]

35. Jorcin, J.-B.; Orazem, M.E.; Pébère, N.; Tribollet, B. Cpe analysis by local electrochemical impedance spectroscopy. Electrochim. Acta 2006, 51, 1473-1479. [CrossRef]

36. Jacob, K.S.; Parameswaran, G. Corrosion inhibition of mild steel in hydrochloric acid solution by Schiff base furointhiosemicarbazone. Corros. Sci. 2010, 52, 224-228. [CrossRef]

37. Duarte, R.; Castela, A.; Neves, R.; Freire, L.; Montemor, M. Corrosion behavior of stainless steel rebars embedded in concrete: An electrochemical impedance spectroscopy study. Electrochim. Acta 2014, 124, 218-224. [CrossRef]

38. Liu, M.; Mao, X.; Zhu, H.; Lin, A.; Wang, D. Water and corrosion resistance of epoxy-acrylic-amine waterborne coatings: Effects of resin molecular weight, polar group and hydrophobic segment. Corros. Sci. 2013, 75, 106-113. [CrossRef]

39. Rammelt, U.; Reinhard, G. Application of electrochemical impedance spectroscopy (EIS) for characterizing the corrosion-protective performance of organic coatings on metals. Org. Coat. 1992, 21, 205-226. [CrossRef]

40. Hosseini, M.; Mertens, S.F.; Ghorbani, M.; Arshadi, M.R. Asymmetrical Schiff bases as inhibitors of mild steel corrosion in sulphuric acid media. Mater. Chem. Phys. 2003, 78, 800-808. [CrossRef]

41. Ashassi-Sorkhabi, H.; Shaabani, B.; Seifzadeh, D. Effect of some pyrimidinicShciff bases on the corrosion of mild steel in hydrochloric acid solution. Electrochim. Acta 2005, 50, 3446-3452. [CrossRef]

42. Bauer, D.R.; Budde, G.F. Crosslinking chemistry and network structure in high solids acrylic-melamine coatings. Ind. Eng. Chem. Prod. Res. Dev. 1981, 20, 674-679. [CrossRef]

(C) 2016 by the authors; licensee MDPI, Basel, Switzerland. This article is an open access article distributed under the terms and conditions of the Creative Commons Attribution (CC-BY) license (http://creativecommons.org/licenses/by/4.0/). 